\title{
PATTERN OF EXPRESSION OF HUMAN HOMOLOGUE OF DROSOPHILA PATCHED1 PROTEIN IN FOUR DIFFERENT SALIVARY GLAND TUMORS
}

\author{
Walid Zedan*
}

\begin{abstract}
Salivary gland tumors are a comparatively rare and diverse group of tumors with variable clinical and histopathological pictures. Pleomorphic adenoma (PA) \& papillary cystadenoma lymphatosum (PCL) are common benign tumors and Mucoepidermoid carcinoma (MEC) \& adenoid cystic carcinoma (ACC) are common malignant tumors with the respect of order. The human homologue of the Drosophila segment polarity gene Patched 1 (PTCH 1) is a member of hedgehog pathway encoding a receptor for the morphogen Sonic Hedgehog and it is the candidate gene for Gorlin's syndrome. Interestingly it is considered as a one of the tumor a suppressor gene which is associated with different neoplasms and cystic lesions. In this study the pattern of expression of PTCH1 in PA, PCL, MEC, and ACC tumors will be explored to reveal if there is any possible correlation between PTCH1 expression and these four different salivary gland entities. Twenty paraffin embedded blocks of salivary gland tumors was chosen as follow (five cases PA, five cases PCL, five cases MEC (two high grades, two low grades, 1 moderate grade) and five cases ACC (4 cribriform pattern, one tubular pattern). immunohistochemistry technique using PTCH 1 primary antibody was done to investigate the level of expression of PTCH 1 protein in our samples. Our results revealed that PTCH1 is expressed with various intensities from light to heavy in the four studied salivary gland tumors. Furthermore, PTCH1 expression was confined to the epithelial cells component of the tumors with cytoplasmic and membranous staining. PCL \& MEC (low \& moderate grade), ACC (cribriform pattern) cases showed the highest immunoreactivity. While PA, high grade MEC, ACC (tubular pattern) showed the lowest. It can be conclude that PTCH1 might has a role in the development of salivary gland tumors with main components epithelium as PCL, MEC, ACC and to a lesser extent PA as a mixed tumor. Finally, it is recommended that researchers should target SHH pathway genes including PTCH1 in most tumors for further investigations and possible gene therapies
\end{abstract}

\section{INTRODUCTION}

Salivary gland tumors are a relatively rare and heterogeneous group of tumors with variable pathologic and phenotypic characteristic in the maxillofacial area with complex morphologic appearance ${ }^{1}$. These tumors comprise $3-6 \%$ of all head and neck neoplasms in various reports ${ }^{2}$. However, they are an important issue in the science

\footnotetext{
* Oral Pathology Department, Faculty of Dentistry, Mansoura University.
} 
of head and neck pathology, due to their difficult diagnosis, management and unpredictable clinical course of disease ${ }^{2}$. Parotid tumors encompass $80 \%$ to $85 \%$ of all salivary gland tumors; almost $75 \%$ of these tumors are benign ${ }^{3}$. Submandibular gland tumors account for $10 \%$ of all salivary gland tumors, but almost half of these are malignant. Less than $1 \%$ of salivary neoplasms develop in the sublingual glands, but $75 \%$ to $80 \%$ of these are malignant. The remainder of salivary gland tumors arises in minor salivary glands, and most of these are malignant ${ }^{3}$.

According to the last World Health Organization (WHO) Head and Neck Tumor Classification was published in $2005^{4}$. Pleomorphic adenoma (PA) \& papillary cystadenoma lymphatosum (PCL) (Warthins tumors) are common benign tumors and Mucoepidermoid carcinoma (MEC) \& Adenoid cystic carcinoma (ACC) are common malignant tumors with the respect of order ${ }^{4}$. PA, PCL affects most often the parotid gland, and is the most frequent benign salivary gland tumors ${ }^{3}$. PA is a mixed tumor consists of epithelial component (duct like, myoepithelial, squamous) and mesenchymal components (fibrous, myxoid, osteoid, chondroid) 5. PCL consists of cystic spaces surrounded by two uniform rows of epithelial cells with centrally placed pyknotic nuclei. The cystic spaces have epithelium referred to as papillary infoldings that protrude into them. Additionally, the epithelium has lymphoid stroma with germinal center formation ${ }^{5}$.

MEC is the most common malignant salivary gland tumor in adults and children. It derives from the main duct segment and is composed of mucous, intermediate, and epidermoid cells in varying combinations. Histologic grading is as follow, low grade with predominance of mucous cells, high grade with the predominance of epidermoid cells and intermediate with equal proportion of the three cell types. The previous grading plays a role in the prognosis of $\mathrm{MEC}^{6}$. ACC, seen most commonly in minor salivary glands, is the second most common malignant salivary gland carcinoma. It appeared in three common histopathological pattern cribriform, solid or tubular pattern. Even though ACC is locally aggressive, with a tendency for perineural invasion, biologic progression is slow, and lymph node metastases are rare. The palate/maxilla is the preferred location for occurrence, and initial clinical presentation at stage IV is common ${ }^{7}$.

The human homologue of the Drosophila segment polarity gene Patched 1 encodes the transmembrane protein (PTCH1), which is a receptor for the morphogen Sonic Hedgehog (Shh) ${ }^{8}$. The Hedgehog (Hh) signaling pathway has essential roles in embryonic development, tissue homeostasis, and tumorigenesis. The pathway is activated by binding of any of the three mammalian Hh isoforms, Sonic Hedgehog (Shh), Indian Hedgehog (Ihh), or Desert Hedgehog (Dhh), to the 12-transmembrane protein Patched-1 (PTCH1) 9. Obviously, Shh/ PTCH signaling controls cell fates, patterning, and growth in several tissues, including teeth ${ }^{10}$. Shh signaling regulates growth and determines the shape of the tooth, but it is not essential for differentiation of ameloblasts or odontoblasts ${ }^{11}$.

Mutations in the PTCH 1 gene were identified as the principal genetic event in nevoid basal cell carcinoma syndrome (Gorlin syndrome) ${ }^{12}$. Demonstration of frequent loss of heterozygosity \& mutations within the region containing the PTCH1 gene, also its protein expression in sporadic and hereditary odontogenic keratocystic tumor (previous odontgenic keratocyst) were identified ${ }^{13-15}$. It had been proved that PTCH1 is a tumor suppressor gene, as revealed by frequent loss-of-function mutations and deletions in basal cell carcinomas, medulloblastoma, and rhabdomyosarcoma 15-18. Moreover, recently PTCH1 had been correlated to the recurrence of breast carcinoma \& hepatocellular carcinoma and it was suggested to had a role in the development of human non-small cell lung cancers, colorectal serrated adenoma, and pancreatic 
neuroendocrine tumor (PNET) ${ }^{19-23}$. Information about the correlation between PTCH1 expression or mutations and salivary gland tumors seems to be deficient.

In this study the pattern of expression of PTCH1 in PA, PCL, MEC, and ACC tumors will be explored to reveal if there is any possible correlation between PTCH1 expression and these four different salivary gland tumors.

\section{MATERIAL AND METHODS}

Tissue Samples of 20 cases of salivary gland tumors was chosen as follow (five cases PA, five cases PCL, five cases MEC (two high grades, two low grades, 1 moderate grade) and five cases ACC (4 cribriform pattern, one tubular pattern) were retrieved from previously diagnosed archival paraffin blocks of Oncology Center, Mansoura University. Each paraffin block was cut for three sections, each of 3 microns thickness. One section was stained with the ordinary Haematoxyline and Eosin (H\&E) stain for the purpose of microscopical evaluation. Other two were one for negative control and the remaining one were processed for immunohistochemical detection of PTCH protein. Immunohistochemical staining laboratory work was done at Leeds Dental Institute, Diagnostic Services Department, Immunohistochemical laboratory.

\section{PTCH antibody}

PTCH1 primary antibody is available at Leeds Dental Institute, Diagnostic Services Department, and Immunohistochemical laboratory. Antibody production polyclonal antibody was raised in rabbit against a human patched peptide from the carboxyterminal region of the protein. A PTCH 1 peptide sequence (C)-N-y-Q-V-D-S-W-E-E-M-LN-K-AE-V-G-H (PTCH peptide) at Leeds Dental Institute. Validation of this antibody was previously described by Zedan et al (2001) ${ }^{13}$.

\section{Immunohistochemical staining}

Tissues used for immunohistochemistry were formalin fixed and paraffin embedded, then incubated in $1 \%(\mathrm{v} / \mathrm{v})$ hydrogen peroxide in methanol for $20 \mathrm{~min}$. The paraffin sections were dewaxed, rehydrated through an alcohol series and then submerged in $6 \mathrm{M}$ urea. This solution was heated to $100^{\circ} \mathrm{C}$ in a microwave, and then cooled for $20 \mathrm{~min}$. Normal goat serum diluted 1:5 in TBS (50mM Tris- $\mathrm{HCl}$ buffer, $\mathrm{pH} 7.5$, containing $0.15 \mathrm{M}$ sodium chloride) was used as blocking agent for 5 min. Sections were then either incubated for 1.5 $\mathrm{hr}$ in 1:40 dilution, or for $16 \mathrm{hr}$ in 1:200 dilution, of affinity purified rabbit anti-PTCH1 primary antibody diluted in TBS. Sections were then washed six times in TBS ( $>5 \mathrm{~min}$ per wash). Detection was carried out with a 1:100 dilution of biotinylated anti-rabbit IgG secondary antibody solution (Dako), for $1 \mathrm{hr}$ at $20^{\circ} \mathrm{C}$. Sections were washed with TBS as above and then incubated with avidinbiotin immunoperoxidase $(10 \mu 1$ solution $\mathrm{A}+10 \mu 1$ solution B in $1000 \mu 1$ of $\mathrm{dH} 2 \mathrm{O}$ [Dako Duet $\mathrm{ABC}$ ]). Immunohistochemical staining was visualised with $70 \mathrm{mM}$ 3,3-diaminobenzidine (Sigma) in $\mathrm{ddH} 2 \mathrm{O}$ for 3-10 min and counter-stained with Mayer's hematoxylin. Negative controls (absence of primary antibody) were run for each slide. Exclusion of the primary antibody was employed as negative control, while normal mucosa was used as positive controls.

Two pathologists independently evaluated the immunohistochemical staining blindly. The intensity of staining was reported as: no staining, -; lightly stained, +; moderately stained, ++; and heavily stained, +++ .

\section{RESULTS}

\section{Histopathological findings}

Examination of haematoxyline and eosin stained sections of the studied 20 cases for the confirmation of the histopathologic pictures of each case as we affirmed before. 


\section{Immunohistochemical results of PTCH1}

Overall evaluation was as follow, PTCH 1 immunoreactivity staining with various intensities from light to heavy in the four studied salivary gland tumors. In most positive salivary tumors tissues examined was observed to show positive intracytoplasmic and membranous staining especially in the epithelial cells components (fig. A \& B \& C) (Table 1).

PA cases in general showed light to negative (+/-) PTCH1 staining in overall tumors components while, mesenchymal components showed negative staining (-). Three cases showed light positive (+), in which epidermoid areas showed a noticeable prominent positivity staining for the keratin pearl in epidermoid cells nest (fig A, 1). Two cases showed negative to light staining (-ve/+).

PCL cases in general showed heavy to moderate PTCH1staining $(+++/++)$ especially in the double layered papillary epithelial cells lining the cystic spaces. Lymphoid cells components in overall cases showed negative staining. Three cases revealed heavy staining of the epithelial components $(+++)$ (fig A, 2), while two cases showed moderate staining $(++)$.

MEC cases in general revealed heavy staining in the low \& moderate and negative to light staining in the high grade cases. Three cases (Two low and one moderate grade) revealed heavy (+++) PTCH1 staining with the predominance of the heavy staining for the epidermal cells clusters and mucous secreting cells, the membranous staining was obvious in the moderate grade one (fig B 1\&2). While the two high grade cases revealed negative to light $(-/+)$ staining PTCH1 staining, especially the highly anaplastic cells showed negative staining (fig B, 3).

ACC cases in general showed moderate to light staining of PTCH1 $(++/+)$. One case of cribriform pattern revealed heavy staining of the small basiloid cells $(+++)$ (fig. C, 1). One case cribriform pattern showed (++). Two cases (one cribriform \& one tubular pattern) showed light staining $(+)$ of PTHC1 (fig $\mathrm{C}, 2$ ). Finally, one case showed moderate staining $(++)$.

TABLE (1) Showing expression pattern of PTCH1 protein in Pleomorphic Adenoma (PA), Papillary Cystadenoma Lymphatosum (PCL), Mucoepidermoid Carcinoma (MEC), and Adenoid Cystic Carcinoma (ACC). Negative staining, -ve; lightly stained, +; moderately stained, ++; and heavily stained, +++.

\begin{tabular}{|l|c|}
\hline \multicolumn{1}{|c|}{ Specimens } & $\begin{array}{c}\text { PTCH1 } \\
\text { immunoreactivity }\end{array}$ \\
\hline PA case 1 & + \\
\hline PA case 2 & $-\mathrm{ve} /+$ \\
\hline PA case 3 & + \\
\hline PA case 4 & + \\
\hline PA case 5 & $-v e /+$ \\
\hline PCL case 1 & ++ \\
\hline PCL case 2 & +++ \\
\hline PCL case 3 & ++ \\
\hline PCL case 4 & +++ \\
\hline PCL case 5 & +++ \\
\hline MEC case 1 (low grade) & +++ \\
\hline MEC case 2 (low grade) & +++ \\
\hline MEC case 3 (moderate grade) & +++ \\
\hline MEC case 4 (high grade) & + -ve \\
\hline MEC case 5 (high grade) & + -ve \\
\hline ACC case 1 (cribriform pattern) & $++/+++$ \\
\hline ACC case 2 (cribriform pattern) & +++ \\
\hline ACC case 3 (cribriform pattern) & ++ \\
\hline ACC case 4 (cribriform pattern) & + \\
\hline ACC case 5 (tubular pattern) & + \\
\hline
\end{tabular}






Fig. A (1) Pleomorphic adenoma showing light PTCH1 staining and a noticeable prominent positivity staining for the keratin pearl in epidermoid cells nest. (2) Warthins tumor revealing heavy PTCH1staining especially in the double layered papillary epithelial cells lining the cystic spaces. Lymphoid cells components showed negative staining. (x200)

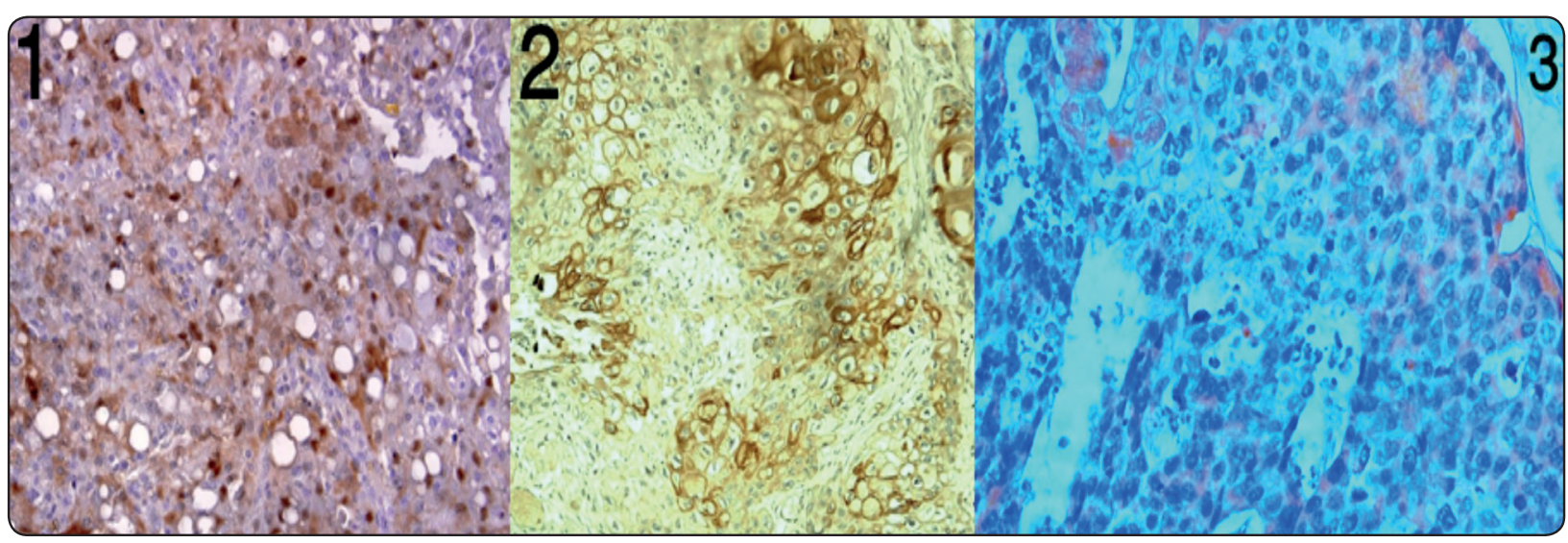

Fig. B (1) \& (2) Low and moderate grade Mucoepidermoid carcinoma showing heavy PTCH1 staining with prominent membranous staining in the epidermal and mucous secreting cells especially in the moderate grade. (3) High grade Mucoepidermoid showing light to negative staining especially in the highly anaplastic cells in the center. (x100,x200,x400)

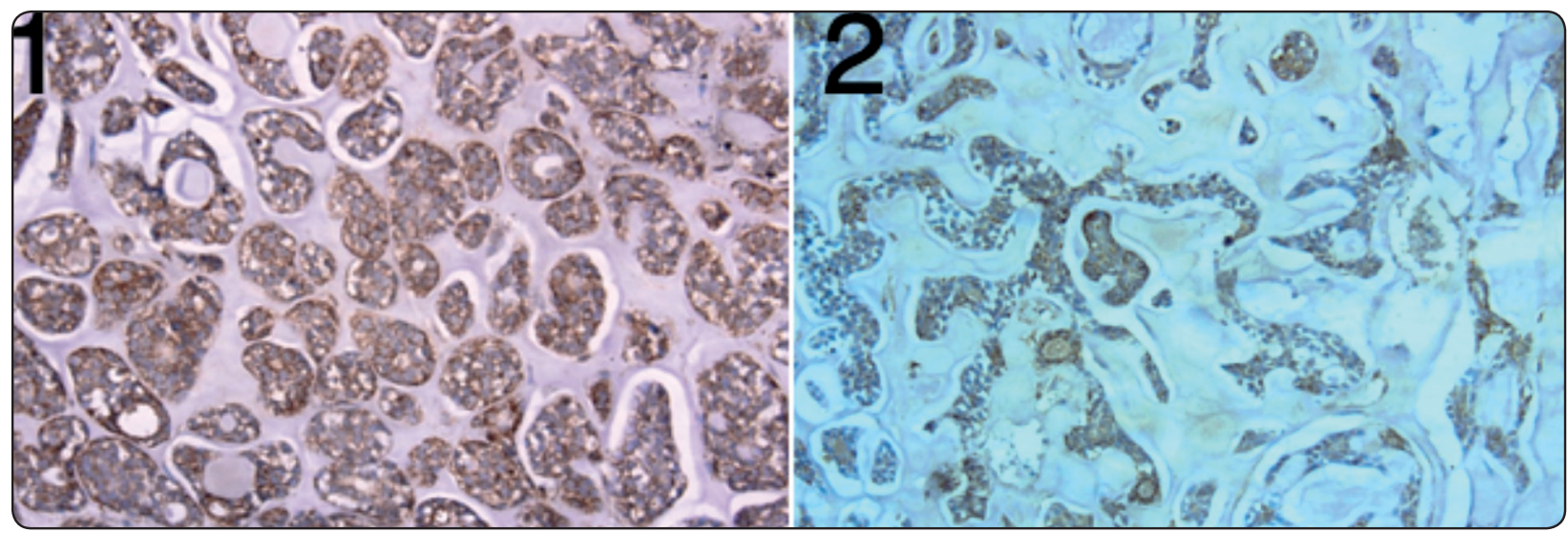

Fig. C (1) Adenoid cystic carcinoma (cribriform pattern) revealed showed heavy PTCH1 staining of the small basiloid cells. (2) Adenoid cystic carcinoma (tubular pattern) showing light staining. (x200) 


\section{DISCUSSION}

PTCH1 is a member of the Sonic Hedgehog signaling pathway (SHH) that controls development and cell fate. Also, PTCH1 had been described as a tumor suppressor gene. Moreover, it had been confirmed to be the candidate gene of nevoid basal cell carcinoma syndrome and related sporadic neoplasms ${ }^{24}$. To date, several studies have provided evidence that PTCH1 might take part in the pathogenesis of a wide variety of neoplasms (benign and malignant) and even cystic lesions ${ }^{13-23}$. From the previous data investigation revealing its expression or mutational analysis in different tumors including salivary gland tumors is needed.

Our study results revealed that PTCH1 is expressed with various intensities from light to heavy in the four studied salivary gland tumors. Furthermore, it was clear that the expression is confined to epithelial cells component of the tumors with cytoplasmic and membranous staining. The previous finding is in agreement with previous data published about the pattern of expression of PTCH1 in Odontogenic keratocystic tumor and basal cell carcinoma both syndromic and sporadic ${ }^{13}$. The fact that PTCH1 is a 12-transmembrane protein is explaining that membranous and cytoplasmic immunoreactivity ${ }^{9}$. However, there is a hypothetic explanation for the nature of accumulated PTCH1 protein as mutational inactivation of PTCH1 leads to overexpression of the mutant transcript owing to failure of a negative feedback mechanism 25,26. Contrary, another hypothesis indicating that accumulations of non-mutated PTCH1 might be sufficient to inhibit expression of PTCH1 and GLI-1 (a down regulated gene in the SHH pathway) by a feedback mechanism, suggesting that $\mathrm{SHH}$ cannot signal effectively in these circumstances ${ }^{27}$.

Our results revealed clearly that PTCH1 is down regulated or less expressed in the PA cases except in the squamous areas. This finding might be explained from our point of view by the diversity and plenty components of PA as a mixed tumor. On the other hand, the heavy immunoreactivity in the squamous areas is in agreement with the fact that most PTCH1 has a main role in the patterning of squamous epithelium morphogenesis ${ }^{28,29}$. Moreover, Kang et al. 2013, postulated that a naturally occurring allele of PTCH1 found in mice promotes early squamous cell carcinoma (SCC) growth without aberrant activation of the SHH pathway. The study reveals new roles for PTCH1 that lie at the nexus between BCC and SCC formation ${ }^{30}$. Previous data might also in agreement with the prominent high expression of PTCH1 in the PCL tumor cases in our study especially the double layered papillary epithelial cells.

MEC cases in our study showed a variable immunoreactivity of PTCH1 a higher expression in low and moderate grade cases and a very low expression in the high grade cases. These finding might be in accordance the data published before about the nature of the PTCH1 expression in malignant tumors as a tumor suppressor gene ${ }^{18}$. Furthermore in agreements with our findings some researches suggesting that PTCH1 gene may be had a truncating mutations proximal to the to the immunogenic sequence of the tested antibody, which leads to lower expression or absence of the whole protein in the course of the highly aneuploidy of the malignant cells which is similarly appeared in P53 antibody ${ }^{13,31}$. Finally, ACC cases showed moderate to light staining of PTCH1 which is to a lesser extents are same of MEC cases results. The rising reports which shown before about the association between PTCH1 mutations or expression in various cancers is supporting our findings ${ }^{15,18,19,20}$.

Constructing all our findings together which indicated that PTCH1 was remarkable expressed with a variable degrees of immunoreactivity in our four tumors entities. Consequently, we can conclude PTCH1 might has a role in the development of the salivary glands tumors with main components epithelium PCL, MEC, ACC and to a lesser extent PA as a mixed tumor. Finally, it is recommended that researchers should target SHH pathway genes including PTCH1 in most tumors for further investigations and possible gene therapies. 


\section{REFERENCES}

1. Spiro RH. Salivary neoplasms: overview of a 35-year experience with 2,807 patients. Head Neck Surg. 1986; $8(3): 177-84$.

2. Regezi JA, Batsakis JG. Histogenesis of salivary gland neoplasms. Otolaryngol Clin North Am. 1977; 10(2):297307.

3. Goyal G, Mehdi SA, Ganti AK. Salivary Gland Cancers: Biology and Systemic Therapy. Oncology 2015; 29(10):773-80

4. Barnes L, Eveson JW, Reichart P et al (eds) (2005). Tumors of the salivary gland. In: Pathology and genetics. Head and neck tumors. World health organization classification of tumors. IARC Press, Lyon, 209-28.

5. Witt, Robert L. (ed.) (2005). "Chapter 9 "Benign tumors, cysts, and tumor-like conditions of the salivary glands". Salivary Gland Diseases: Surgical and Medical Management. New York: Thieme Medical Publishers. p. 123.

6. Brandwein MS, Ivanov K, Wallace DI, Hille JJ, Wang B, Fahmy A, et al. Mucoepidermoid carcinoma: A clinicopathologic study of 80 patients with special reference to histological grading. Am. J. Surg.Pathol. 2001; 25:835-45.

7. Shum JW, Chatzistefanou I, Qaisi M, Lubek JE, Ord RA. Adenoid cystic carcinoma of the minor salivary glands: a retrospective series of 29 cases and review of the literature. Oral Surg Oral Med Oral Pathol Oral Radiol. 2015; 22. pii: S2212-4403(15)01244-4.

8. Stone DM, Hynes M, Armanini M, Swanson TA, Gu Q, Johnson RL, et al. The tumour-suppressor gene patched encodes a candidate receptor for sonic hedgehog. Nature 1996; 384:129-134.

9. Carpenter D, Stone DM, Brush J, Ryan A, Armanini M, Frantz G, Rosenthal A, de Sauvage FJ. Characterization of two patched receptors for the vertebrate Hedgehog protein family. Proc. Natl. Acad. Sci. U. S. A., 1998; 95:1363013634.

10. Bitgood MJ, McMahon AP. Hedgehog and Bmp genes are coexpressed at many diverse sites of cell-cell interaction in the mouse embryo. Dev Biol 1995; 172:126-138.

11. Lench NJ, High AS, Markham AF, Hume WJ, Robinson PA. Investigation of chromosome 9q22.3-q31 DNA marker loss in odontogenic keratocysts. Oral Oncol. 1996; 32B: 202-206.
12. Hahn H, Wicking C, Zaphiropoulos P, Gailani MR, et al. Mutations of the human homologue of Drosophila patched in the nevoid basal cell carcinoma syndrome. Cell 1996; 85: 841-851.

13. Zedan W, Robinson PA, Markham AF, High AS. Expression of the Sonic Hedgehog receptor 'PATCHED' in basal cell carcinomas and odontogenic keratocysts. J. Pathol., 2001; 194:473-477.

14. Pan S, xu LL, Sun LS, Li TJ. Identification of known and novel PTCH mutations in both syndromic and nonsyndromic keratocystic odontogenic tumors. Int. J. Oral Sci. 2009; 1(1):34-8.

15. Gailani MR, Stahle-Backdahl M, Leffell DJ, Glynn M, Zaphiropoulos PG, Pressman C, Undén AB, Dean M, Brash DE, Bale AE, Toftgård R.. The role of the human homologue of Drosophila patched in sporadic basal cell carcinomas. Nat. Genet. 1996; 14:78-81.

16. Johnson RL, Rothman AL, Xie J, Goodrich LV, Bare JW, Bonifas JM, Quinn AG, Myers RM, Cox DR, Epstein EH, Jr, Scott MP.. Human homolog of Patched, a candidate gene for the basal cell nevus syndrome. Science 1996; 272:1668-1671.

17. Goodrich LV, Milenkovic L, Higgins KM, Scott MP.. Altered neural cell fates and medulloblastoma in mouse patched mutants. Science 1997; 277:1109-1113. 10.

18. Belyea B, Kephart JG, Blum J, Kirsch DG, Linardic CM. Embryonic signaling pathways and rhabdomyosarcoma: contributions to cancer development and opportunities for therapeutic targeting. Sarcoma 2012:406239.

19. Jeng KS, Sheen IS, Jeng WJ, Yu MC, Hsiau HI, Chang FY. High expression of Sonic Hedgehog signaling pathway genes indicates a risk of recurrence of breast carcinoma. Onco Targets Ther. 2013; 27;7:79-86.

20. Jeng KS, Sheen IS, Jeng WJ, Lin CC, Lin CK, Su JC, Yu MC, Fang HY. High expression of patched homolog-1 messenger RNA and glioma-associated oncogene-1 messenger RNA of sonic hedgehog signaling pathway indicates a risk of postresection recurrence of hepatocellular carcinoma. Ann Surg Oncol. 2013; 20(2):464-73.

21. Hong Z, Bi A, Chen D, Gao L, Yin Z, Luo L. Activation of hedgehog signaling pathway in human non-small cell lung cancers. Pathol Oncol Res. 2014; 20(4):917-22.

22. Morimoto T, Mitomi H, Saito T, Takahashi M, Murakami T, Sakamoto N, Yao T, Watanabe S. Distinct profile of 
HIF1 $\alpha$, PTCH, EphB2, or DNA repair protein expression and BRAF mutation in colorectal serrated adenoma. J Gastroenterol Hepatol. 2014; 29(6):1192-9.

23. Gurung B, Hua X, Runske M, Bennett B, LiVolsi V, Roses R, Fraker DA, Metz DC. PTCH 1 staining of pancreatic neuroendocrine tumor (PNET) samples from patients with and without multiple endocrine neoplasia (MEN-1) syndrome reveals a potential therapeutic target. Cancer Biol Ther. 2015;16(2):219-24.

24. Gache Y, Brellier F, Rouanet S, Al-Qaraghuli S, Goncalves-Maia M, Burty-Valin E, Barnay S, Scarzello S, Ruat M, Sevenet N, Avril MF, Magnaldo T. Basal Cell Carcinoma in Gorlin's Patients: a Matter of FibroblastsLed Protumoral Microenvironment? PLoS One. 2015; 22;10(12):e0145369. doi: 10.1371

25. Undén AB, Zaphiropoulos PG, Bruce K, Toftgard R, Stahle-Backdahl M. Human patched (PTCH) mRNA is overexpressed consistently in tumor cells of both familial and sporadic basal cell carcinoma. Cancer Res. 1997; 57:2336-2340.

26. Nagano T, Bito T, Kallassy M, Nakazawa H, Ichihashi M, Ueda M. Overexpression of the human homologue of Drosophila patched (PTCH) in skin tumours: specific- ity for basal cell carcinoma. Brit. J. Dermatol. 1999; 140: 287-290.

27. Goodrich LV, Jung D, Higgins KM, Scott MP. Overexpression of PTC 1 inhibits induction of Shh target genes and prevents normal patterning in the neural tube. Dev Biol 1999; 211: 323-334.

28. Oro AE1, Higgins K. Hair cycle regulation of Hedgehog signal reception. Dev Biol. 2003; 15;255(2):238-48.

29. Uhmann A, Heß I, Frommhold A, König S, Zabel S, Nitzki F, Dittmann K, Lühder F, Christiansen H, Reifenberger J, Schulz-Schaeffer W, Hahn H. DMBA/TPA treatment is necessary for BCC formation from patched deficient epidermal cells in Ptch (flox/flox) CD4 Cre (+/-) mice. J Invest Dermatol. 2014; 134(10):2620-9

30. Kang H. C., Wakabayashi Y, Jen K., Mao J., Zoumpourlis V., Del Rosario R., and Balmain A. Ptch1 overexpression drives skin carcinogenesis and developmental defects in K14PtchFVB mice. J Invest Dermatol. 2013; 133(5): 1311-1320.

31. Iggo R, Gatter K, Bartek J, Lane D, Harris AL. Increased expression of mutant forms of p53 oncogene in primary lung cancer. Lancet 1990; 335: 675-679 